\title{
BARREIRAS INCOMENSURÁVEIS? UM COMENTÁRIO
}

\author{
AN INCOMMENSURABLE DIVIDE? A COMMENTARY
}

\section{Everton Rangel Maria Elvira Díaz-Benitez ${ }^{1}$}

O convite para que comentássemos este ensaio de Saba Mahmood nos colocou num impasse. Um bom impasse, certamente. O objetivo da autora é pensar o conflito entre a necessidade secular e a ameaça religiosa, ou melhor, questionar os modos com que corriqueiramente pensamos essa divisão a partir de ideários normativos tanto sobre o secular, quanto sobre o religioso e, mais fundamentalmente, sobre o modo secular de conceber o extremismo religioso. O que se vê é uma análise rica, que mostra como, de fato, esses mundos não existem sobre bases tão binárias assim. Mahmood mostra como as saídas jurídicas para a "resolução" de conflitos estão permeadas de modos seculares e hierárquicos de ativar a lei e de interpretar as culturas e a diferença. Ela mostra como a vivência muçulmana da injúria não suscita perguntas relevantes no contexto da publicação dos cartuns dinamarqueses que satirizavam o profeta Muhammad, tendo sido obscurecida pelo discurso da "liberdade de expressão". Ser muçulmano na Europa é possível apenas por meio da assimilação? Pergunta Mahmood. Ou seria viável por meio de "uma transformação mais ampla nas sensibilidades culturais e éticas da maioria da população judaico-cristã, que sustentam a lei”? (Mahmood, neste volume).

Se nos sentimos em um impasse ao tentar comentar o texto é porque haveriam várias saídas para este fim. Poderíamos discutir, através dos argumentos da autora e de outros (Asad, 2003, 2011; Asad et al., 2009; Reinhardt, 2017; Connolly, 1999), as relaçôes entre secularismo e religião. Poderíamos

1 Everton Rangel é doutorando no Programa de Pós-Graduação em Antropologia Social do Museu Nacional da UFRJ, Rio de Janeiro, Brasil. E-mail: era.rangel@gmail.com. María Elvira Díaz-Benítez é docente no mesmo Programa. E-mail: blueananse@yahoo.com.

Debates do NER, Porto Alegre, ano i9, N. 36, P. 79-90, Ago./DeZ. 20 i 9 
interpretar este ensaio à luz de sua obra, de sua antropologia engajada na interpretação dos valores éticos e culturais dos mundos árabes, como os do Egito, em sua relação crítica com valores liberais, incluindo o feminismo. Ou poderíamos tentar refletir sobre a sensação de angústia que nos produziu a leitura de um texto que fala sobre o mundo construído a partir de grandes divisores. Que mundo comum é possível compartilhar? Como podemos fazê-lo? Ou, como disse Achille Mbembe: "Como pensar a diferença e a vida, o semelhante e o dessemelhante, o excedente e o em comum?” (2018, p. 23). Optamos por seguir este último caminho.

\section{O QUE HÁ PARA ALÉM DAS VIRTUDES?}

A virada que Mahmood propóe em direção à ética deriva de movimentos político-intelectuais que, ao menos na antropologia, produziram um afastamento da ênfase estrutural. A centralidade assumida pelas abordagens que reconhecem a natureza histórica das sensibilidades e dos repertórios de ação disponíveis culminaram muitas vezes em apostas de cunho fenomenológico, isto é, preocupadas com a descrição do que Lambek (2015) chamou de “tonalidades da vida”. A obra de Foucault (1980, 1982, 1988), dentre outros filósofos, é particularmente cara à Mahmood, já que evidencia a possibilidade e a relevância de nos perguntarmos sobre as experiências de sujeição, mais precisamente sobre o paradoxo de tornarmo-nos sujeitos através das normas que nos habitam e habilitam as nossas ações sem determinar as cores precisas das mesmas. É esse o postulado que parece sustentar a ideia de pensar a agência como correlacionada às capacidades encorporadas [embodied]; aos meios de formação do sujeito; à ética enquanto conjunto de práticas que redundam em estilos de vida. Quando a ética está correlacionada às virtudes, diz a autora, devemos nos perguntar menos sobre o que ela significa e mais sobre o que ela faz, causa ou provoca. Nesse sentido, as práticas virtuosas são positividades porque permitem às pessoas operarem um conjunto de açóes sobre si mesmas, visando alcançarem um estilo de ser, uma dada forma de 
sentir e pensar compartilhada localmente. Parece-nos que o trabalho de si sobre si mesmo não é bem compreendido se percebido como algo puramente individual, um autocentramento ou uma renúncia ao outro. Trata-se, antes, da presença do outro em si, de um trabalho que não se faz completamente sozinho e que, no limite, está destinado ao outro, ou melhor, depende da existência do outro para que seja efetuado.

Em outra publicação (Díaz-Benítez; Rangel; Fernandes, 2018), fizemos alusão à crítica de Schielke (2009) à etnografia de Mahmood enquanto produto intelectual revelador de "histórias de sucesso", isto é, focado na descrição de práticas virtuosas relativamente bem efetuadas. Nosso objetivo era o de demarcar que o foco na ética das virtudes pode encobrir a análise dos custos subjetivos associados à conquista dos modos de conduzir a si considerados bons e belos em determinados contextos sociais. Pensávamos naqueles sujeitos desgastados pelas promessas das normas no mundo capitalista e naquelas apostas políticas na negatividade como modalidade de evasão (Halberstam, 2011): um deixar de ser, por um lado, fomentado pelo caráter desigual e excludente das possibilidades de reconhecimento e, por outro lado, aplaudido como estratégia de enfrentamento às políticas liberais. Contrastávamos as histórias de sucesso às histórias de falência, considerando quais imaginaçóes políticas os autores acionam e normatizam. Buscávamos assim chamar atenção às ambivalências que constituem a vida daqueles sujeitos que, mesmo desgastados, seguem esperando e lutando por dias melhores, por futuros incertos. Usávamos a palavra ambivalência para demonstrar que o fazer dos sujeitos não está em necessária relação de oposição ao desfazer dos mesmos, nem o questionamento das fórmulas de sucesso e felicidade independe da compreensão das formas de participação e relativa adequação às normas que muitas vezes são associadas ao liberalismo. $O$ fato é que a palavra ambivalência pode tanto ser uma qualidade intrínseca dos fenômenos, como pode ser apenas uma linguagem vaga e imprecisa, uma falha da própria capacidade de um antropólogo ou outro de descrever os fenômenos (Strathern, 1999). 
Se não há como saber o que de fato significa o uso da palavra ambivalência, a não ser de etnografia em etnografia, é fundamental explicitar uma abordagem que nos inspira e que pode inspirar descriçôes que nos parecem de suma importância. A ideia de que os eventos críticos não surgem do nada, nem esvanecem sem baixar ao cotidiano (Das, 2007), é digna de nota porque nos faz ver que episódios como o da publicação das imagens satíricas do profeta Muhammad podem ser analisados a partir das controvérsias que evocam, mas também a partir do modo como lançam seus tentáculos em direção à vida ordinária. Pensando nesse segundo sentido, encontramos no esforço descritivo de Mahmood uma linguagem política para tratar daquilo que sentiram os muçulmanos que viveram os ataques à imagem do profeta como injúrias voltadas diretamente a eles mesmos, uma vez que a relaçáo entre essas pessoas e a imagem caracteriza-se pela mútua constituição. A relação dos devotos com Muhammad é uma forma de "habitar o mundo, corporal e eticamente" (Mahmood, neste volume) vivida náo como mandamento, mas como virtude, como similitude. Assim, blasfemar a imagem do profeta é blasfemar uma figura de imanência, uma relação de copresença. Mahmood explica esse vínculo ao ícone a partir da noção de schesis de Aristóteles, que qualifica uma relação com a figura autoral do Profeta por meio de um sentido de intimidade e desejo, um trabalho de amor, e não como resposta a uma compulsáo da lei. No texto que nos foi sugerido comentar é possível perceber a relevância política e ética atribuída ao trabalho do amor, mas não é possível através dele perceber possibilidades concretas de reconhecimento dessa virtude em seus próprios termos cosmológicos, o que culmina na crítica elaborada pela autora às sensibilidades seculares $\mathrm{e}$ seu controle das formas de expressão da religiosidade.

Reafirmar o apelo à transformaçáo das sensibilidades feito por Mahmood requer, para além da identificação de práticas virtuosas, insistir que ainda há muito por dizer sobre o que é viver com aqueles de quem não conseguimos ou não podemos nos afastar completamente, mesmo que nos causem dor. $\mathrm{O}$ chamado que estamos fazendo é o de voltarmos nossas descriçôes aos sabores, cores e custos do que é viver com quem estamos em profundo "desacordo" 
ou mesmo nos ameaça. O Brasil de 2019 é um exemplo poderoso para pensar a este respeito. Quantos de nós nos indignamos com a atuação e as ideologias da família que está no poder, bem como com os múltiplos sujeitos que, unidos a eles rizomaticamente, atuam em estados e municípios, em ministérios, secretarias e afins. Quantos são os que enunciam frases taxativas, estilo: "tenho nojo desses evangélicos" e "odeio o pentecostalismo"? Por sua vez, quantos deles acusam qualquer posição ou opinião nossa como gesto de "comunista", de pessoas "do mal", de "petralha" que quer acabar com o "pouco que resta do Brasil"? O que vivemos agora é a experiência palpável do Grande Divisor, a redução provocada pelo teatro realista do nós contra eles, a sensação de que existe uma diferença inegociável, de que estamos vivendo numa luta do bem contra o mal. Nesse horizonte, se existem diferenças entre ser evangélico ou pentecostal, tanto faz, botamos tudo no mesmo saco com a maior tranquilidade. Se somos de centro, de esquerda ou simplesmente contrários às políticas do governo atual, tanto faz, porque segundo o ângulo de observação dos nossos opositores podemos representar uma ameaça de grande potencial. Facilmente nos convertemos, diante dos seus olhos, em uma manifestação do "extremismo secular", e nós, certamente, ao assistirmos os efeitos dos seus programas de extermínio de tudo aquilo em que acreditamos em termos de educação, saúde, emprego, gênero, corrupção, sexualidade, segurança e qualidade de vida, entre outros, nos sentimos interpelados por "extremistas religiosos".

$\mathrm{E}$, assim, a guerra começa - se não no plano do corpo a corpo como de fato é vivido enfaticamente pelas minorias de classe, raça/etnia, gênero/ sexualidade nas cidades e nas zonas rurais do país - no terreno da linguagem. Injuriamos, ofendemos, humilhamos. Ou, então, utilizamos as gramáticas da paródia como resposta sempre possível àquilo que representa um risco social (McClintock, 2010).

Esse é um lado da moeda, a experiência sensorial de um cotidiano que nos empurra a tomar atitudes e a acionar pensamentos que obscurecem a possibilidade de respondermos de modo otimista a pergunta: que mundo é possível compartilhar? Sugerimos pensar que esse é o cotidiano dos eventos 
críticos. Com essa expressão fazemos referência à rotinização dos acontecimentos políticos que nos apavoram e nos governam através das frases de efeito, das notícias alarmantes, das incitaçôes constantes ao medo, da perda real e imaginada de um futuro outrora enunciado. Paralelamente, vivemos em um outro cotidiano, aquele relativo às relaçóes de vizinhança e intimidade, e é este cotidiano que, por vezes, desafia o grande divisor e nos faz questionar nossas sensibilidades frente ao outro. $\mathrm{O}$ que ameaça o cotidiano das relaçôes de vizinhança, intimidade ou proximidade é a hipermetropia mútua, a incapacidade de enxergar ao outro de perto, ou a nossa incompetência para visualizar que o vizinho evangélico, aquele que ajudou a eleger o presidente, talvez não te queira morto, mesmo que você seja uma bicha preta. Poderíamos dar inúmeros exemplos e emaranhar mais ainda a questáo indagando como, entre os progressistas, há também racismo. Como entre os gays, há bolsonarismo. Ou como, entre os pentecostais, há micropolíticas de solidariedade racial e as igrejas podem ser também espaços relevantes para o empoderamento feminino. Enfim, o que queremos dizer com isto é apenas que é a esse cotidiano das relaçóes de contiguidade que as nossas sensibilidades afetivas e éticas se voltam para fazer um mundo possível, mesmo em meio aos grandes divisores que nos constituem - nesse cotidiano dos eventos críticos - e que, aparentemente, não estamos dispostos a abdicar.

Quando Veena Das (2018) propôs observarmos as "texturas da vida" — expressão que lembra aquela usada por Lambek (2015), "tonalidades da vida" - ela pensava que nenhum cotidiano se oferece ao conhecimento de modo direto, já que as coisas de todos os dias comportam opacidade e anunciam a sua presença, mais ou menos como o tempo que, não sendo palpável, exibe a si mesmo a partir do trabalho que efetua nos corpos e nas paisagens. Porque o cotidiano precisa ser imaginado, isto é, não existe como fato empírico dado, as modalidades de imaginação do mesmo apontam para os diferentes modos como a intimidade pode ser descrita, e não só ela. Isso é particularmente interessante porque acentua que as texturas assumidas pelo ordinário são múltiplas e que a imaginação antropológica constrói e limita o que chama de hábito, espécie de sensibilidade encorporada e repetitiva. 
Acreditamos que o esforço de desnaturalização do hábito é parte necessária da tarefa de entender como, onde, quando, por quê e em quais circunstâncias estamos dispostos ou não a atender aos mais variados chamados do outro, dos nossos vizinhos que hoje já não são quem uma vez foram para a gente. Se há criatividade vinculada às pequenas transformaçôes do hábito, aos deslocamentos infinitesimais do comportamento, o próprio cotidiano guarda algo misterioso e certa volatilidade em sua superfície. $\mathrm{O}$ que as pessoas fazem para năo deixar que os seus desapontamentos se tornem a totalidade da vida? Pergunta-se Das (2018). Como o mundo comum é ameaçado, desfeito e reparado, sem que sejam apagadas as memórias doloridas do que foi vivido junto?

\section{VIVER JUNTOS NA QUEBRA: POR UMA ÉTICA ABAIXO-COMUM}

No ensaio que originou este comentário, Mahmood levanta outra questão que queremos destacar: a do tratamento racista que recebe o povo muçulmano na Europa e a da negaçáo secular deste mesmo tratamento, sob o argumento de que a religiáo não é biologia e que, não sendo biologia, não teria nada a ver com raça. A religiáo, sob esse ângulo, seria um assunto de escolha pessoal. Se Mahmood reteve esta última colocaçáo sobre a escolha para a elaboração de sua crítica, nós queremos reter a ideia da racializaçáo da diferença, e ao redor disto discorrer para finalizar este breve texto.

A pergunta que nos move diz respeito às derivas daqueles para os quais a reparação do cotidiano não é uma possibilidade real. O que é o comum para as pessoas que tiveram o seu cotidiano tornado crítico em sua inteireza? Quais são as formas de compartilhar um mesmo mundo quando as possibilidades de futuro de uns estâo radicalmente mais ameaçadas que as de outros?

Em Sobre el terrorismo suicida (On suicide bombing), Talal Asad (2008) se pergunta: Por que o Ocidente responde aos atentados suicidas com um horror 
excepcional, mas não manifesta a mesma emoção diante das crueldades das ditaduras, das democracias, dos sistemas penais e carcerários, das políticas de imigração, das limpezas étnicas, das torturas e das guerras imperiais? Os motivos para o ato suicida são, segundo suposições liberais, atribuídos às subjetividades religiosas islâmicas através de ideias como as de "martírio" e "sacrifício"; que se assemelham a ideários cristãos sobre o "tornar-se sagrado" e, como explica o autor, são elementos do imaginário político do nacionalismo moderno (Asad, 2008, p. 68). Encontrar uma explicação pela via da religiáo, aludindo a elementos psicológicos, a tradiçóes familiares e signos culturais, é fundamental para os discursos sobre a proteção da civilização contra a barbárie. Isso parece uma saída mais simples do que aceitar que, se

o capitalismo industrial é a condição volátil sob a qual as liberdades Ocidentais têm sido construídas, defendidas e outorgadas ao mundo, [...] porque o Estado soberano moderno possui um direito absoluto a defender-se e essa defesa pode comportar, legitimamente, a utilização de armas nucleares, a guerra suicida, com incalculáveis consequências planetárias, existe, no mundo liberal, como uma possibilidade legítima. (Asad, 2008, p. 77).

O que está em jogo, concordam Asad e Mahmood, são sensibilidades que separam o que é digno de dor ou de ser visto com horror, daquilo que não é, e a criação de justificativas para a perpetuação dessas visóes. Assim, o mundo que conhecemos está habitado por uma enormidade de contingentes humanos relegados à linha da sobrevivência e obrigados a viver com outros contingentes que os desejam mortos. Falamos de sujeitos e naçôes unidas à vida por uma divida impagável. Essa noção, divida, tem sido desenvolvida pela antropóloga Denise Ferreira da Silva (2017), e por Stefano Harney e Fred Moten (2013) em relação ao sujeito negro e à experiência da colonização que se reatualiza em diversos atos necropolíticos. Está presente também na obra de Octavia Butler, Kindred (2019), que nos lembra, evocando Fanon, o quanto o corpo dos sobreviventes é sempre um corpo amputado. O problema da descolonização, nos lembra Achille Mbembe (2019), é que ela acontece mantendo os dispositivos mentais que legitimaram a sua domi- 
nação, perpetuação esta que impede os povos africanos e afrodescendentes de "sair da grande noite". Essas estruturas racistas de pensamento, percepção e comportamento "[...] recomeçam a aparecer hoje em dia no contexto das controvérsias sobre o Islâ, o uso do véu ou da burca, a questão dos banlieues, da imigração e da identidade" (Mbembe, 2019, p. 251). Sabemos que não é possível descolonizar sem desracializar. Mbembe chama esse movimento de percepçáo legitimante da dominação e da divisão hierárquica da diferença humana de o princípio de raça:

[S] ob vários aspectos, nosso mundo continua a ser, mesmo que não o queira admitir, um 'mundo de raças'. O significante racial ainda é, em larga medida, a linguagem incontornável, mesmo que por vezes negada, da narrativa de si mesmos e do mundo, da relação com o outro, com a memória e com o poder. (Mbembe, 2018, p. 106).

Quais estratégias são possíveis para os corpos unidos simbolicamente pelo princípio de raça? Mahmood (2005) entende que habitar a norma é uma forma de agência para além da prerrogativa — liberal — da resistência. Outras éticas entendem que a norma é aquilo que historicamente tem criado seres quebrantados e que mais do que resistir à norma ou habitá-la, é necessário não reconhecê-la. Estaríamos entrando no âmbito de uma ética abaixo-comum, que, como Harvey e Moten (2013) descrevem, seria aquela que se constrói a partir de uma quebra (que é fratura, e simultaneamente, divida) para a qual não existe reparação. Produto da governança — isto é, a instituição dos modos de governo da branquitude ou dos modos com que a racialização foi instituída como política e transformada em poder —, a quebra se perpetua porque a violência da pretitude é inseparável da própria governança.

A essas violências, os abaixo-comuns respondem com a técnica fugitiva. O fugitivo abaixo-comum é aquele que nada tem, apenas a materialidade de sua própria vida, aquele que foi expropriado inclusive de uma humanidade que não consegue alcançar. Sua fuga não restaura a ordem, mas anuncia uma violência cíclica que persiste. E enquanto o racismo existir e o corpo 
racializado continuar a significar uma propriedade para o capitalismo, haverá o movimento de fuga. Nessa fuga, o abaixo-comum entende que o mundo implica um trauma, e reconhece sua vida expropriada em outra vida expropriada que é negra, mas também indígena (e que, se unidos pelo principio de raça, pode ser palestina, pobre, LGBT...).

A vida na quebra supóe desde aí se construir algo novo que não parta da procura pelo reconhecimento da branquitude, mas do derrubamento dessa estrutura de reconhecimento que afirma a supremacia. Que náo parta de uma oposiçáo à norma, mas de "habitar esse afora indômito para além das estruturas que habitamos e que nos habitam" (Halberstam, 2013, p. 7), significa rechaçar aquilo que tem sido negado e aquilo que tem sido oferecido.

Barreiras incomensuráveis? A essa pergunta a ética abaixo-comum responderia que habitar a quebra em conjunto deverá possibilitar novas formas de imaginação, e que são necessárias coalizóes em que aquele que ostenta o poder abra mão não apenas de seu poder, mas do ponto de vista no qual esse poder faz sentido.

\section{REFERÊNCIAS}

ASAD, Talal. Formations of the secular: Christianity, Islam, modernity. Stanford, CA: Stanford University Press, 2003.

ASAD, Talal. Sobre el terrorismo suicida. Barcelona: Editorial Laertes, 2008. ASAD, Talal. Thinking about the secular body, pain, and liberal politics. Cultural Anthropology, Arlington, VA, v. 26, n. 4, p. 657-675, 2011.

ASAD, Talal; BROWN, Wendy; BUTLER, Judith; MAHMOOD, Saba. Is critique secular?: blasphemy, injury, and free speech. Berkeley: University of California, 2009. (Townsend Papers in the Humanities, n. 2).

BUTLER, Octavia. Kindred: laços de sangue. Sáo Paulo: Morrobranco Editora, 2019. 
CONNOLLY, William. Why I am not a secularist. Minneapolis: University of Minnesota Press, 1999.

DAS, Veena. Ethics, self-knowledge, and life taken as a whole. $H A U$ : Journal of Ethnographic Theory, Chicago, IL, v. 8, n. 3, p. 537-549, 2018.

DAS, Veena. Life and words: violence and the descent into the ordinary. Berkeley: University of California Press, 2007.

DÍAZ-BENÍTEZ, María Elvira; RANGEL, Everton; FERNANDES, Camila. Governo, desejo, afeto. In: RANGEL, Everton; FERNANDES, Camila; LIMA, Fátima (org.). (Des) Prazer da norma. Rio de Janeiro: Papéis Selvagens Ediçôes, 2018. p. 11-44.

FOUCAULT, Michel. História da sexualidade I: a vontade de saber. Rio de Janeiro: Ediçóes Graal, 1980.

FOUCAULT, Michel. História da sexualidade II: o uso dos prazeres. Rio de Janeiro: Ediçôes Graal, 1988.

FOUCAULT, Michel. The subject and power. Critical Inquiry, Chicago, IL, v. 8, n. 4, p. 777-795, 1982.

HALBERSTAM, Jack. The queer art of failure. Durham: Duke University Press, 2011.

HALBERSTAM, Jack. The wild beyond: with and for the undercommons. In: HARNEY, Stefano; MOTEN, Fred. The undercommons: fugitive planning and black study. New York: Minor Compositions, 2013. p. 7-12.

HARNEY, Stefano; MOTEN, Fred. The undercommons: fugitive planning and black study. New York: Minor Compositions, 2013.

LAMBEK, Michael. Lecture 1: living as if it mattered. In: LAMBEK, Michael; DAS, Veena; FASSIN, Didier; KEANE, Webb. Four lectures on Ethics: anthropological perspectives. Chicago: Hau Books by Chicago Press, 2015. Cap. 1. 
MAHMOOD, Saba. Politics of piety: the Islamic revival and feminist subject. Princeton: Princeton University Press, 2005.

MBEMBE, Achille. Crítica da razão negra. São Paulo: Editora n-1, 2018.

MBEMBE, Achille. Sair da grande noite: ensaio sobre a África descolonizada. Rio de Janeiro: Editora Vozes, 2019.

MCCLINTOCK, Anne. Couro imperial: raça, gênero e sexualidade no embate colonial. Campinas: Editora Unicamp, 2010.

REINHARDT, Bruno. Afetos seculares. Religiāo \& Sociedade, Rio de Janeiro, v. 37, n. 1, p. 167-174, jan./abr. 2017.

SCHIELKE, Samuli. Being good in Ramadan: ambivalence, fragmentation, and the moral self in the lives of Young egyptians. The Journal of the Royal Anthropological Institute, Hoboken, v. 15, n. 1, p. S24-S40, 2009.

SILVA, Denise Ferreira da. A divida impagável: lendo cenas de valor contra a flecha do tempo. São Paulo: Oficina de Imaginação Política, 2017.

STRATHERN, Marilyn. No limite de uma certa linguagem. Mana, Rio de Janeiro, v. 5, n. 2, p. 157-175, out. 1999.

Recebido em: 29/10/2019

Aprovado em: 29/10/2019 